Trong nghiên cứu của Hanakita xạ phẫu trên 22 bệnh nhân u màng não không điển hình, tỷ lệ kiểm soát tại thời điểm 1 năm là $74 \%, 2$ năm là $39 \%, 5$ năm là $16 \%{ }^{4}$. Báo cáo của Park xạ phẫu Gamma Knife đối với u màng não sau phấu thuật cho thấy tỷ lệ tái phát đối với u màng não độ cao là $32 \%{ }^{5}$. Trong nghiên cứu của chúng tôi, với thời gian theo dõi trung bình 13 tháng (7-21 tháng), có 3 bệnh nhân tái phát (12,5\%), trong đó gồm $2 / 21$ bệnh nhân u màng não độ II và $1 / 3$ bệnh nhân u màng não độ III. Tỷ lệ kiểm soát tại thời điểm 1 năm là $94,1 \%$. Kết quả này cũng phù hợp với các nghiên cứu của các tác giả khác.

\section{KẾT LUẬN}

Xạ phẫu Gamma Knife kiểm soát tại chỗ hiệu quả đối với u màng não độ cao.

\section{TÀI LIÊU THAM KHẢO}

1. Modha A, Gutin PH. Diagnosis and treatment of atypical and anaplastic meningiomas: a review. Neurosurgery. Sep 2005;57(3):538-50; discussion 538-50.doi:10.1227/01.neu.0000170980.47582.a5.

2. Louis DN, Perry A, Reifenberger G, et al. The 2016 World Health Organization Classification of
Tumors of the Central Nervous System: a summary. Acta neuropathologica. Jun 2016; 131(6): 803-20. doi:10.1007/s00401-016-1545-1.

3. Perry A, Stafford SL, Scheithauer BW, Suman VJ, Lohse CM. Meningioma grading: an analysis of histologic parameters. The American journal of surgical pathology. Dec 1997;21(12):1455-65. doi:10.1097/00000478-199712000-00008.

4. Hanakita $S$, Koga $T$, Igaki $H$, et al. Role of gamma knife surgery for intracranial atypical (WHO grade II) meningiomas. Journal of neurosurgery. Dec 2013;119(6):1410-4. doi: 10.3171/2013.8.JNS13343.

5. Park CK, Jung NY, Chang WS, Jung $\mathbf{H H}$, Chang Jw. Gamma Knife Radiosurgery for Postoperative Remnant Meningioma: Analysis of Recurrence Factors According to World Health Organization Grade. World neurosurgery. Dec 2019;132:e399-e402. doi:10.1016/j.wneu.2019.08.136.

6. Wilson TA, Huang $L$, Ramanathan $D$, et al. Review of Atypical and Anaplastic Meningiomas: Classification, Molecular Biology, and Management. Frontiers in oncology. 2020;10:565582. doi:10.3389/fonc.2020.565582.

7. Hasan S, Young M, Albert T, et al. The role of adjuvant radiotherapy after gross total resection of atypical meningiomas. World neurosurgery. May 2015;83(5):808-15. doi:10.1016/j.wneu.2014.12.037.

\title{
KHẢO SÁT THỰC TRẠG BÁN LẺ THUỐC DỰA TRÊN TÌNH HUỐNG MUA THUỐC KỂ ĐƠ'N TẠI CÁC NHÀ THUỐC TƯ NHÂN TRÊN ĐỊA BÀN HUYÊ̂N CỦ CHI, THÀNH PHỐ HỒ CHÍ MINH
}

\section{TÓM TẮT}

Đặt vấn đê: Nghiên cứu được thực hiện nhằm có được cái nhìn tổng quan về thực trạng bán lẻ thuốc của nhân viên bán hàng (NVBHi) trền địa bàn huyện Củ Chi, từ đó đề ra các giải pháp phù hợp nhằm nâng cao chất lượng cung ứng thuốc cho cộng đồng. Đối tượng và phương pháp nghiên cứu: Nghiển cứu cắt ngang mô tả quan sát trực tiếp NVBH đang làm việc tại 279 nhà thuốc tư nhân trên địa bàn huyện Củ Chi từ 11/2020 - 06/2021 và thu thập kết quả nghiên cứu gồm đặc điểm NVBH, kết quả giao dịch của NVBH dựa trên việc đóng vai khách hàng với tình huống yêu cấu mua thuốc nhỏ mắt kê đơn Tobradex. Kết quả: Khảo sát 317 nhân viên bán hàng với tỷ lệ nam: nữ 1: 3,3; độ tuổi trung bình 33,58 $\pm 6,80$ tuổi; $60,9 \%$ là dược sĩ trung học; 69,4\% chưa tứng tham gia bất kỳ lớp tập huấn về kỹ năng bán lẻ thuốc và 30,3\% chưa từng tham gia lớp đào tạo, cập nhật kiến thức về GPP.

*Đai hoc Y Dước TP.HCM

Chịu trách nhiệm chính: Nguyễn Thị Thu Thủy

Email: nguyenthuthuy@ump.edu.vn

Ngày nhận bài: 2.8.2021

Ngày phản biện khoa học: 30.9.2021

Ngày duyệt bải: 6.10 .2021
Võ Thảo Nguyên*, Nguyễn Thị Thu Thủy*

Về kết quả giao dịch, 47,0\% NVBH không yêu câu trình đơn thuốc khi được yêu câuu bán thuốc Tobradex, trong đó $97,3 \%$ đồng ý cung cấp sản phẩm gồm $57,7 \%$ thay thế Tobradex bằng một thuốc kê đơn khác; $28,9 \%$ bán Tobradex đúng yều câu và $10,7 \%$ bán Tobradex kèm thuốc khác. Kết luân: Nghiên cứu cho thấy thực trạng thực hiện nguyển tắc GPP của NVBH tai các nhà thuốc tư nhân trên đia bàn huyên Củ Chi còn nhiều bất cập. Vì vậy, cần nâng cao kiến thức, kỹ năng của NVBiH và thúc đầy việc thực hiện nghiêm túc nguyên tắc GPP tại các nhà thuốc cộng đồng.

Tư khóa: bán lẻ thuốc, dược sĩ cộng đồng, nhà thuốc tư nhân, thuốc kê đơn, Tobradex.

\section{SUMMARY \\ SURVEY THE RETAILING STATUS WITH \\ PRESCRIPTION DRUG SITUATION AT \\ PRIVATE PHARMACIES IN CU CHI DISTRICT, HO CHI MINH CITY}

Background:The study was carried out to get an overview on the current situation of drug retailing at private pharmacies in CuChi district, thereby proposing solutions to improving quality of drug supply. Method: A cross - sectional descriptive study by directing observation of community pharmacists, working at 279 private pharmacies in CuChi district 
from Nov-2020 to Jun-2021 and collecting data including their characteristics and transaction results based on playing the role of customer, requiring a prescription eye-drop drug (Tobradex) scenario. Results: The sample of 317 community pharmacists has gender difference between male: female with the ratio of 1:3.3; average age of $33.58 \pm 6.80$ years old; $60.9 \%$ pharmacists with intermediate level; $69.4 \%$ pharmacists having not attended any training course of drug retailing skills and $30.3 \%$ having not attended training course of updating GPP. Regarding to transaction results, $47.0 \%$ pharmacists did not require medical prescription; $97.3 \%$ of them agreed to provide drug, in which $57.7 \%$ replaced Tobradex by another prescription drug, $28.9 \%$ sold Tobradex as required and $10.7 \%$ sold Tobradex with another drug. Conclusion: This study has shown that community pharmacists and pharmacies did not strictly follow GPP principle. Therefore, it is necessary to improve the knowledge and skills of community pharmacists and promote the implementation of GPP principles in community pharmacies.

Keywords: drug retail, community pharmacist, private pharmacy, prescription drugs, Tobradex.

\section{I. ĐĂT VẤN ĐỀ}

Ơं Việt Nam, cũng như nhiều nước đang phát triển, cơ sở bán lẻ thuốc thường là nguồn thông tin chăm sóc sức khỏe đầu tiên mà người dân có thể tiếp cận khi xuất hiện triệu chứng bệnh, đặc biệt quan trọng với những vùng xa xôi nhất trển đẩt nước. Tại Việt Nam năm 2011 số lượng nhà thuốc trên toàn quốc đạt hơn 40.000 (với khoảng 12.000 nhà thuốc tư nhân) và tăng lên gấp 1,4 lần tương đương với 54.250 vào năm 2015[4], [5]. Chính vì vậy vai trò của dược sĩ cộng đồng ngày càng được đề cao với nhiều yêu cầu chặt chẽ hơn cả về năng lực chuyên môn lẫn kỹ năng thực hành.

Hiện nay, mặc dù rất nhiều đề tài nghiên cứu về thực trạng bán lẻ thuốc tại các nhà thuốc tư

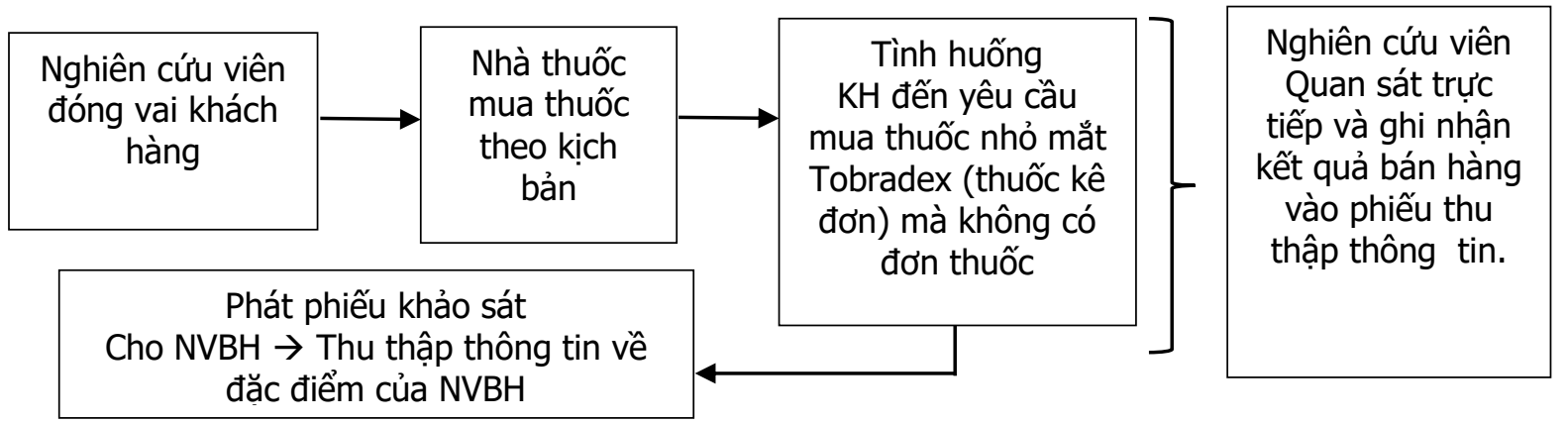

Hình 1. Quy trinh tiến hành khảo sát thu thập thông tín

Kịch bản tình huống: Điều tra viên vào nhà thuốc và hỏi mua 1 chai nhỏ mắt Tobradex cho em trai (25 tuổi) với triệu chứng mắt trái bị đỏ, ngứa, cảm giác khó chịu và không đi khám tại cơ sở y tế, biết được thuốc do tìm hiểu trên mạng. nhân được thực hiện, nhưng chưa có nghiên cứu nào thực hiện trên thực trạng bán lẻ thuốc, nhất là thuốc kê đơn dựa trên tình huống mua thuốc nhất định. Vì vậy đề tài này được thực hiện nhằm khảo sát thực trạng bán lẻ thuốc dựa trền tình huốn mua thuốc kề đơn tại các nhà thuốc tư nhân trên địa bàn huyện Củ Chi - một huyện ngoại thành thuộc Tp. Hồ Chí Minh (TP.HCM), từ đó đề ra các giải pháp phù hợp nhằm nâng cao chất lượng cung ứng thuốc cho cộng đồng. Nghiên cứu này được thực hiện với 2 mục tiêu cụ thể như sau:

1. Khảo sát đặc điểm của nhân viên bán hàng tại các nhà thuốc tư nhân trên địa bàn huyện Củ Chi, TP.HCM.

2. Khảo sát thực trạng bán lẻ thuốc dựa trên tình huống mua thuốc kê đơn Tobradex tại các nhà thuốc tư nhân trên địa bàn huyện Củ Chi, TP.HCM.

\section{II. ĐỐI TƯỢNG VÀ PHƯƠNG PHÁP NGHIÊN CỨU \\ Đối tượng nghiên cứu. Kết quả bán lẻ} thuốc dựa trên tình huống mua thuốc kê đơn Tobradex và đặc điểm nhân viên bán hàng thực hiện giao dịch tại thời điểm nghiên cứu tại tất cả các nhà thuốc tư nhân trên địa bàn huyện Củ Chi, TP.HCM.

Phương pháp nghiên cứu. Nghiên cứu cắt ngang mô tả dựa trên quan sát trực tiếp quá trình bán và tư vấn khách hàng mua thuốc kê đơn Tobradex và phiếu thu thập thông tin. Nghiên cứu viên đóng vai khách hàng $(\mathrm{KH})$ dựa trên kịch bản tình huống, qua đó quan sát trực tiếp NVBH đang làm việc tại các nhà thuốc tư nhân và thu thập kết quả nghiên cứu. Trình tự nghiên cứu được trình bày trong hình 1 .

Nếu nhà thuốc không có sản phẩm Tobradex, nghiên cứu viên phải chấp nhận bất kỳ lời đề nghị từ NVBH.

\section{Mẫu nghiên cứu}


Cõ̃ mẫu. Tại 279 nhà thuốc tư nhân đang hoạt động trên địa bàn huyện Củ Chi theo danh sách của Sở y tế TP HCM cập nhật ngày $16 / 12 / 2019^{[3]}$, đề tài khảo sát tất cả NVBH thỏa tiêu chí chọn mẫu trong thời gian nghiên cứu đang làm việc tại các nhà thuốc tư nhân có giấy phép kinh doanh còn hiệu lực, đạt chuẩn GPP đang hoạt động trên địa bàn huyện Củ Chi, TPHCM. Nghiên cứu không thực hiện khảo sát tại nhà thuốc bệnh viện/trong khuồn viên bệnh viện, các cơ sở bán lẻ dược liệu/thuốc đông y, các đại lý bán thuốc, chuỗi nhà thuốc, nhà thuốc của cổng ty dược phẩm.

Tại mỗi nhà thuốc tư nhân, quá trình khảo sát được thực hiện cho $1 \mathrm{NVBH}$ tại mỗi ca làm việc. Nếu một ca có nhiêu hơn 1 NVBH cùng lúc, chỉ tiến hành khảo sát cho 1 NVBH cho ca làm việc đó.

\section{Tiêu chí chọn mẫu:}

\section{Tiêu chí lưa chon:}

- NVBH đang làm việc tại các nhà thuốc tư nhân tại thời điểm tiến hành khảo sát.

- NVBH trực tiếp thực hiện việc bán và tư vấn sử dụng thuốc

\section{Tiêu chí loai trư}

- NVBH không đồng ý cung cấp thông tin phục vụ nghiên cứu

- Quá trình bán và tư vấn bi gián đoạn do nguyên nhân từ phía NVBH

- Nhiều hơn 1 NVBH tham gia trong quá trình bán và tư vấn khách hàng

Thời gian và địa điểm nghiên cứu

Thời gian: nghiên cứu được thực hiện từ tháng 11/2020 - 06/2021.

Địa điểm: thực hiện tại các nhà thuốc tư nhân trên địa bàn huyện Củ Chi, TP.HCM

Thống kê và xử lý số liệu. Dữ liệu được xử lý thống kê bằng phần mềm thống kê SPSS 20.0 với kêt quả được trình bày dưới dạng hình và bảng.

\section{KẾT QUẢ NGHIÊN CỨU}

Đặc điểm của nhân viên bán hàng tại các nhà thuốc trên địa bàn huyện Củ Chi, TP.HCM. Khảo sát 279 nhà thuốc tư nhân đang hoạt động trên địa bàn huyện Củ Chi, đề tài thu thập mẫu nghiên cứu gồm 317 NVBH đang làm việc tại thời điểm tiến hành khảo sát. Các đặc điểm về giới tính, tuổi tác và chuyên môn nghề nghiệp của NVBH tham gia khảo sát được trình bày trong bảng 1 .

Bảng 1. Đặc điểm của nhân viên bán hang

\begin{tabular}{|c|c|c|c|}
\hline STT & Đặc điếm & Phân loại & Tân số(\%) \\
\hline \multirow{2}{*}{1} & Giới tính & Nam & $73(23,0)$ \\
\cline { 3 - 4 } 2 & Trình độ & Dược sĩ sau đại học & $244(77,0)$ \\
\hline
\end{tabular}

\begin{tabular}{|c|c|c|c|}
\hline \multirow[t]{4}{*}{ 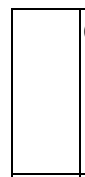 } & \multirow[t]{4}{*}{ chuyên môn } & Dược sĩ đại học & $39(12,3)$ \\
\hline & & Dược sĩ cao đằng & $76(24,0)$ \\
\hline & & Dược sĩ trung học & $193(60,9)$ \\
\hline & & Dược tá và y sĩ & $7(2,2)$ \\
\hline \multirow[b]{3}{*}{3} & \multirow{3}{*}{$\begin{array}{l}\text { Chức vụ } \\
\text { trong nhà } \\
\text { thuốc }\end{array}$} & Chủ nhà thuốc & $223(69,3)$ \\
\hline & & NVBH & $95(29,5)$ \\
\hline & & $\begin{array}{l}\text { Chủ nhà thuốc kiêm } \\
\text { dược sĩ phụ trách }\end{array}$ & $4(1,2)$ \\
\hline \multirow{5}{*}{4} & \multirow{5}{*}{$\begin{array}{l}\text { Mức độ yêu } \\
\text { thích công } \\
\text { việc }\end{array}$} & 1.Rất không thích & $1(0,3)$ \\
\hline & & 2.Không thích & $5(1,6)$ \\
\hline & & 3.Trung bình & $93(29,3)$ \\
\hline & & 4.Thích & $161(50,8)$ \\
\hline & & 5.Rất thích & $57(18,0)$ \\
\hline \multirow[b]{2}{*}{5} & \multirow{2}{*}{$\begin{array}{c}\text { Lớp tâp } \\
\text { huấn kỹ } \\
\text { năng bán lẻ } \\
\text { thuốc }\end{array}$} & Không tham gia & $220(69,4)$ \\
\hline & & Có tham gia & $97(30,6)$ \\
\hline \multirow[b]{2}{*}{6} & \multirow{2}{*}{$\begin{array}{l}\text { Lớp đào } \\
\text { tạo, cập } \\
\text { nhật GPP }\end{array}$} & Không tham gia & $96(30,3)$ \\
\hline & & Có tham gia & $221(69,7)$ \\
\hline \multirow{3}{*}{7} & \multirow{3}{*}{$\begin{array}{c}\text { Mức độ tự } \\
\text { cập nhâât } \\
\text { kiến thức } \\
\text { chuyên môn } \\
\end{array}$} & Dưới 3 lần/tuần & $22(6,9)$ \\
\hline & & 1 - 2 lần/tuân & $81(25,6)$ \\
\hline & & Chỉ khi cần & $214(67,5)$ \\
\hline \multirow{4}{*}{8} & \multirow{4}{*}{$\begin{array}{l}\text { Thâm niên } \\
\text { kinh nghiệm } \\
\text { trong lînh } \\
\text { vực bán lẻ }\end{array}$} & Dưới 1 năm & $5(1,6)$ \\
\hline & & $\begin{array}{c}\text { Từ } 1 \text { đến dưới } 2 \\
\text { năm }\end{array}$ & $21(6,6)$ \\
\hline & & Từ 2 đến dưới 5 năm & $74(23,3)$ \\
\hline & & Trên 5 năm & $217(68,5)$ \\
\hline & & \multicolumn{2}{|c|}{ GTTB \pm ĐLC (GTNN-GTLN) } \\
\hline 9 & Tuổi & $33,58 \pm 6,80$ & $3-56)$ \\
\hline 10 & $\begin{array}{l}\text { Số năm sau } \\
\text { khi tốt } \\
\text { nghiệp }\end{array}$ & \multicolumn{2}{|c|}{$8,24 \pm 4,88(1-30)$} \\
\hline
\end{tabular}
lệch chuẩn

GTNN-GTLN: Giá trị nhỏ nhất-Giá trị lớn nhất.

Theo bảng 1 , đề tài ghi nhận mẫu nghiên cứu với 317 NVBH làm viêc tại các nhà thuốc tư nhân trên địa bàn có sự chênh lệch về giới tính với tỉ lệ nam: nữ là 1: 3,3; độ tuổi trung bình 33,58 \pm 6,80 tuổi và dao động từ 23 đến 56 tuổi. Đa số NVBH là dước sĩ trung học $(60,9 \%)$ với thời gian sau tốt nghiệp trung bình $8,24 \pm 4,88$ năm (dao động từ 1 đển 30 năm). Gần $70 \% \mathrm{NVBH}$ có kinh nghiệm làm việc trên 5 năm với $69,4 \% \mathrm{NVBH}$ chưa từng tham gia lớp tập huấn về kỹ năng bán lẻ thuốc và $30,3 \%$ chưa từng tham gia lớp đào tạo, cập nhật kiến thức về GPP; hơn 60\% tự cập nhật kiến thức chuyên môn khi cần. Về chức vụ trong nhà thuốc, người bán là chủ nhà thuốc chiếm gần $2 / 3$ tổng số mẫu nghiên cứu, người 
trực tiếp đứng bán vừa là chủ vừa là dược sĩ phụ trách chuyên môn của nhà thuốc chiếm $1,2 \%$. Về mức độ yêu thích công việc, $68,8 \%$ đánh giá từ thích trở lên và $31,2 \%$ đánh giá mức trung bình trở xuống.

Thực trạng bán lẻ thuốc kê đơn (Tobradex) của nhân viên bán hàng tại các nhà thuốc tư nhân trên địa bàn huyện Củ Chi, TP.HCM. Tỷ lệ yêu cầu trình đơn thuốc và chấp nhận bán thuốc

Thống kê 317 lượt giao dịch giữa NVBH với nghiên cứu viên, đề tài ghi nhận tỷ lệ NVBH yêu cầu trình đơn thuốc và trình bày trong hình 2 .

Bảng 2. Kêt quả giao dịch của NVBH

\begin{tabular}{|c|c|c|c|c|}
\hline \multicolumn{2}{|c|}{ Kết quả giao dịch } & $\begin{array}{l}\text { Yêu câu trình đơn } \\
\text { thuốc } n=168(53,0)\end{array}$ & $\begin{array}{l}\text { Không yêu câu trình đơn } \\
\text { thuốc } n=149(47,0)\end{array}$ & p-value \\
\hline \multirow{2}{*}{\multicolumn{2}{|c|}{$\begin{array}{c}\text { BÁN } \\
\text { KHÓNG BÁN }\end{array}$}} & $157(93,5)$ & $145(97,3)$ & 0,403 \\
\hline & & $11(6,5)$ & $4(2,7)$ & 0,098 \\
\hline \multirow{2}{*}{$\begin{array}{r}\text { Lí } \\
\text { do }\end{array}$} & Hết hàng & $5(3,0)$ & $4(2,7)$ & 0,876 \\
\hline & Không có đơn thuốc & $6(3,5)$ & $0(0,0)$ & 0,020 \\
\hline
\end{tabular}

Theo bảng 2 , trong nhóm yêu cầu trình đơn thuốc, mặc dù người mua thuốc không có đơn thuốc theo kịch bản, 93,5\% đồng ý bán thuốc và $6,5 \%$ không đồng ý bán thuốc. Như vậy tỷ lệ không đồng ý bán thuốc rất thấp; trong đó có 3,5\% không bán vì lý do không trình đơn thuốc và $3,0 \%$ vì lý do không có sản phẩm yêu cầu. Trong nhóm không yêu cầu trình đơn thuốc, $2,7 \%$ không bán thuốc vì lý do không có thuốc và $97,3 \%$ đồng ý cung cấp sản phẩm. Đề tài ghi nhận tỷ lệ không cung cấp sản phẩm vì lý do khổng có đơn thuốc ở nhóm yêu cầu trình đơn thuốc $(3,5 \%)$ cao hơn có ý nghĩa thống kê so với nhóm không yêu cầu trình đơn thuốc $(0,0 \%)$ với $p<0,05$. Việc mua thuốc kê đơn bắt buộc phải trình đơn thuốc là yêu cầu chuyên môn theo GPP. Tuy nhiên mặc dù không có đơn thuốc, đa số NVBH vẫn thực hiện việc bán thuốc kê đơnn, chỉ có $1,9 \% \mathrm{NVBH}$ trên toàn mẫu không bán thuốc vì lý do không trình đơn thuốc.

Kết quả bán lẻ thuốc kê đơn Tobradex

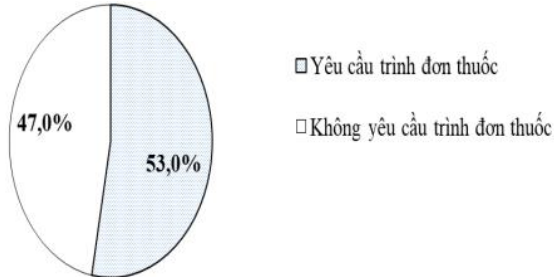

Hình 2. Tỉ lệ NVBH có và không yêu cầu trinh đơn thuốc $(N=317)$

Theo hình 2, trong tổng số 317 NVBH được khảo sát, 53,0\% chủ động yêu cầu trình đơn thuốc và $47,0 \%$ không yêu câu trình đơn thuốc dù Tobradex thuộc nhóm thuốc kê đơn. Kết quả giao dịch được trình bày trong bảng 2 .
Về kết quả bán lẻ thuốc kê đơn Tobradex, đề tài ghi nhận các kết quả bán thuốc của NVBH được trình bày trong hình 3 .

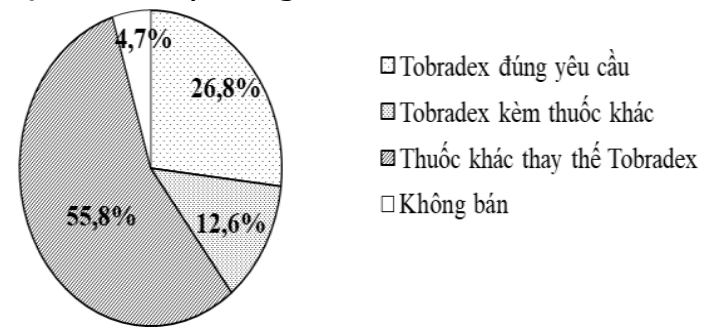

Hình 3. Kêt quả bán lẻ thuốc kê đơn Tobradex $(N=317)$

Theo hình 3, đề tài ghi nhận 4,7\% không bán; $26,8 \%$ bán Tobradex theo đúng yêu câu từ $\mathrm{KH} ; 55,8 \%$ bán một thuốc khác thay thế Tobradex, và $12,6 \%$ bán Tobradex kèm theo một thuốc khác.

Phân tích chi tiết kết quả giao dịch ở nhóm có và không có yêu cầu trình đơn thuốc, đề tài ghi nhận kết quả được trình bày trong bảng 3 .

Bảng 3. Kết quả giao dịch của NVBH có cung cấp sản phẩm $(N=317)$

\begin{tabular}{|c|c|c|c|c|}
\hline \multicolumn{2}{|c|}{ Kết quả bán hàng } & $\begin{array}{c}\text { Yêu câu } \\
\text { trình đớn thuốc } \\
n=168(53,0)\end{array}$ & $\begin{array}{l}\text { Không yêu câu } \\
\text { trình đơn thuốc } \\
n=149(47,0)\end{array}$ & $\begin{array}{c}\mathbf{p -} \\
\text { value }\end{array}$ \\
\hline \multicolumn{2}{|c|}{ BÁN } & $157(93,5)$ & $145(97,3)$ & \\
\hline \multirow{2}{*}{\multicolumn{2}{|c|}{$\begin{array}{l}\text { Tobradex đúng yêu câu } \\
\text { Tobradex + thuốc khác }\end{array}$}} & $42(25,0)$ & $43(28,9)$ & 0,440 \\
\hline & & $24(14,3)$ & $16(10,7)$ & 0,344 \\
\hline \multirow{2}{*}{$\begin{array}{l}\text { Nhóm nhỏ } \\
\text { mắt }\end{array}$} & Bố sung vitamin & $3(1,8)$ & $1(0,7)$ & 0,376 \\
\hline & Nước muối nhỏ mắt & $11(6,5)$ & $6(4,0)$ & 0,315 \\
\hline \multicolumn{2}{|c|}{ Nhóm viên uống bố mắt } & $7(4,2)$ & $8(5,4)$ & 0,616 \\
\hline
\end{tabular}




\begin{tabular}{|c|c|c|c|c|}
\hline \multirow{2}{*}{\multicolumn{2}{|c|}{$\begin{array}{c}\text { Mỡ tra măt } \\
\text { Thuốc khác thav thế Tobradex }\end{array}$}} & \multirow{3}{*}{$\begin{array}{c}3(1,8) \\
91(54,2) \\
8(48)\end{array}$} & \multirow{3}{*}{$\begin{array}{c}1(0,7) \\
86(57,7) \\
6(4,0)\end{array}$} & \multirow{2}{*}{$\begin{array}{l}0,376 \\
0,527\end{array}$} \\
\hline & & & & \\
\hline \multirow{2}{*}{$\begin{array}{c}\text { Thuốc } \\
\text { nhỏ mắt } \\
\text { kê đơn }\end{array}$} & $\begin{array}{c}\text { Có } 2 \text { thành phần tương tự } \\
\text { Tobradex }\end{array}$ & & & 0,751 \\
\hline & Chỉ có 1 hoạt chất Tobramycin & $69(41,1)$ & $67(45,0)$ & 0,486 \\
\hline \multirow{2}{*}{\multicolumn{2}{|c|}{$\begin{array}{c}\text { Thuốc nhỏ mắt không kê đơn } \\
\text { Viên uống bố măt }\end{array}$}} & $14(8,3)$ & $12(8,1)$ & 0,928 \\
\hline & & $0(0,0)$ & $1(0,7)$ & 0,319 \\
\hline
\end{tabular}

Theo bảng 3, đề tài ghi nhận trong số NV không yêu câu trình đơn thuốc $28,9 \%$ bán Tobradex đúng yêu câu; $10,7 \%$ bán Tobradex kèm thêm thuốc khác; $57,7 \%$ NV thay thế Tobradex bằng một thuốc khác. Ở nhóm NVBH yêu cầu trình đợn thuốc, $25,0 \%$ vẫn bán Tobradex theo yêu cầu dù không có đơn thuốc, 14,3\% bán Tobradex kèm thêm một thuốc khác và $54,2 \%$ thay thế Tobradex bằng một thuốc khác.

Các thuốc bán kèm với Tobradex bao gồm nhóm nhỏ mắt (nước muối $0,9 \%$, vitamin V.Rohto Lycee), viên uống bổ mắt (Galepo, vitamin $A-D$ ) và mõ tra mắt (Tetracyclin). Đế tài không ghi nhận sự khác biệt có ý nghĩa thống kê trong tỷ lệ các nhóm thuốc bán kèm ở 2 nhóm NVBH yểu cầu và không yêu cầu trình đơn thuốc. Trong đó đa số NVBH bán kèm viên uống bổ mắt hoặc nước muối nhỏ mắt.

Các thuốc bán thay thế Tobradex bao gồm thuốc nhỏ mắt kê đơn khác với 2 hoạt chất tương tự (Tobidex) hoặc với 1 hoạt chất tương tự (Biracin - E, Torexvis - D, Tobrex); thuốc nhỏ mắt không kê đơn (Osla, Eskar); viên uống bổ mắt (Galepo, Vitamin $A-D$ ). Đề tài không ghi nhận sự khác biệt có ý nghĩa thống kê trong tỷ lệ các nhóm thuốc thay thế ở 2 nhóm NVBH yêu cầu và không yêu cầu trình đơn thuốc $(p>0,05)$. Trong đó đa số thay thế bằng thuốc có một hoạt chất tương tự tobramycin (chiếm $41,1 \%$ ở nhóm yêu cầu trình đơn thuốc và $45,0 \%$ ở nhóm không yêu câuu trình đơn thuốc); có $8,3 \%$ ở nhóm yêu cầu trình đơn thuốc và $8,1 \%$ ở nhóm không yêu câu trình đơn thuốc thay thế bằng thuốc nhỏ mắt không kê đơn.

\section{BÀN LUÂ̂N}

Từ những thực trạng bán lẻ thuốc dựa trên tình huống mua thuốc kê đơn đề tài ghi nhận $47,0 \%$ NV không yêu cầu trình đơn thuốc và $97,3 \%$ trong số đó vẫn cung cấp sản phẩm cho $\mathrm{KH}$ cho thấy thực trạng kém tuân thủ nguyên tắc "Thực hành tốt cơ sở bán lẻ thuốc - GPP" do Bộ $Y$ tể ban hành của NVBH trên địa bàn huyện Củ Chi xuất phát từ việc NV chưa được tập huấn kỹ trước khi hành nghề ${ }^{[2]}$. Ngoài việc bán đúng Tobradex theo yêu cầu, 55,8\% NVBH vẫn dể dàng thay thế Tobradex bằng một thuốc khác với đa số tự chỉ định thuốc kê đơn có hoạt chất tương tự. Bên cạnh đó, tỉ lệ NV chủ động yêu cầu trình đơn và có quyết định không bán vì lý do không trình được đớn thuốc chỉ chiếm 1,9\% trên tổng số NV được khảo sát là một con số đáng báo động vì trên thực tế, đây là kết quả được khuyến khích nhất để có thể hạn chế việc sử dụng kháng sinh tràn lan và thực hiện đúng quy định bán thuốc kê đơn của NVBH.

Như vậy, thông qua tình huống mua thuốc nhỏ mắt kê đơn Tobradex, đề tài đã ghi nhận các kết quả bán hàng của NV và cho thây thực trạng bán lẻ thuốc kê đơn tại các nhà thuốc tư nhân hiện nay trên địa bàn khảo sát. Đề tài được thực hiện bằng phương pháp quan sát nên kết quả nghiên cứu đã thể hiện một cách khách quan kết quả bán hàng thực tế của NVBH. Tuy nhiên, đề tài chỉ mới ghi nhận kết quả giao dịch ở tình huống bán thuốc kê đợn giữa nhóm NV có và không yêu cầu trình đớn thuốc nhưng phân tích các yếu tố liên quan đến kết quả bán lẻ thuốc của NVBH.

\section{KẾT LUẬN}

Nghiên cứu ghi nhận thực trạng thực hiện nguyên tắc GPP của NVBH làm việc tại các nhà thuốc tư nhân trên địa bàn huyện Củ Chi chưa nghiêm ngặt với $47 \%$ NV không yêu cầu trình đơn thuốc và chỉ có $1,9 \%$ NV không đồng ý bán thuốc kê đơn vì lý do không có đơn thuốc. Vì vậy, cần nâng cao kiến thức, kỹ năng của NVBH và thúc đẩy việc thực hiện nghiêm túc nguyên tắc GPP tại các nhà thuốc cộng đồng.

\section{TÀI LIẸU THAM KHẢO}

1. Bộ Y tế (2017), "Tăng cường kiểm soát kê đơn thuốc và bán thuốc kê đ̛ơn giai đoạn 2017-2020".

2. Bộ Y tế (2018), "Thông tư số 02/2018/TT-BYT qưy định vê "Thực hành tốt cơ sở bán lẻ thuốc".

3. Sở Y tế TP.HCM (2019), "Danh sách các nhà thuốc năm 2019-2020".

4. Nguyen Tuan Anh et al. (2017), "Pharmaceutical Policy in Vietnam", Pharmaceutical Policy in Countries with Developing Healthcare Systems, pp. 75-94.

5.Tran Van De et al. (2019), "Factors influencing community pharmacists' recommendation of overthe-counter medications in four Vietnam cities", Tropical Journal of Pharmaceutical Research. 18 (2). 